\title{
An Approach to Evaluate Exhibition Lighting Alternatives: The Case of Museum of Palace Collections
}

\section{Taner Çelikmez* Leyla Dokuzer Öztürk ${ }^{* \star}$}

\section{Abstract}

\section{Purpose}

Museums collect, preserve, analyse, and exhibit works of art and historical values. There are numerous publications that offer guidance on museum lighting to balance exhibition and preservation requirements.

Some guidelines such as the way of control of illuminance on threedimensional artefacts, the acceptable illuminance uniformity, and the limiting values for direct glare are missing in literature on museum lighting. The aim of this study is to suggest limiting values for the mentioned lighting requirements, describe the way of lighting control on 3D objects, and to present an approach to evaluate different lighting alternatives in terms of conservation, accurate perception of artworks, and energy consumption.

\section{Design/Methodology/Approach}

The evaluation of various lighting alternatives was carried out by reference to the Museum of Palace Collections. The lighting alternatives that can be applied in the exhibition hall of the museum were investigated in the first phase of the study. Twelve lighting
Keywords: Energy efficiency, glare, illuminance, museum lighting, showcase lighting

*M.Sc in Department of Architecture, Faculty of Architecture, Yıldız Technical University, Istanbul, Turkey.

E-mail: tanercelikmez@gmail.com ORCID No: https://orcid.org/00000001-7014-3400

${ }^{* *}$ Ph.D in Department of Architecture, Faculty of Architecture, Ylldız Technical University, Istanbul, Turkey.

E-mail: dokuzer@yildiz.edu.tr ORCID No: https://orcid.org/00000002-4484-7727 
arrangement alternatives have been design ed and modelled by means of DIALux lighting software and the results were obtained in terms of preservation, lighting design criteria, and energy consumption. An approach has been developed in which all considered criteria were assessed separately. The results of twelve lighting arrangements were compared according to the presented approach. The number of lighting design criteria that met the requirements and their degree of fulfilment were considered in comparison. Subsequently, the optimal lighting alternatives were determined.

\section{Findings}

The results acquired in the twelve arrangements designed via the lighting program were compared with respect to illuminance level and uniformity, direct glare, reflected glare, shadow properties, perceptibility of the hall, and energy efficiency. Taking into account all the mentioned criteria the optimum lighting arrangements for the conditions of this study were determined as 'indirect general lighting and showcase lighting with horizontal linear luminaire behind the upper metal profile', followed by 'indirect general lighting and showcase lighting with horizontal linear lamp behind the opal glass '.

\section{Research Limitations/Implications}

So as to limit the conditions of the study, the existing showcase types and the exhibition design were kept constant. It is obvious that more lighting alternatives can be created by considering other types of showcases and exhibition design in addition to the existing ones.

\section{Practical Implications}

The evaluation process proposed in this study and discussed using the Museum of Palace Collections as an example can be followed to make the most rational decision regarding the illumination of other exhibition halls.

\section{Social Implications}

One of the main objectives of museum lighting is to assure the visitors perceive the properties of exhibited objects comfortably and completely. The perceptibility of the exhibition hall itself can also be important especially if it has historical value and/or exceptional architecture. Rational decisions for artificial lighting ensure that the hall and the artefacts displayed within it are fully and comfortably perceived and consequently visitors can benefit as much as possible from the exhibition.

\section{Originality/Value}

In this study, some missing guidelines for museum lighting are proposed and an approach is presented to evaluate possible different lighting alternatives for exhibition halls. Finally, the importance of simultaneous architectural-, interior-, lighting- and display design is emphasized.

\section{INTRODUCTION}

It is important to ensure that works of art and historical values inherited from the past and safely to be handed over to the future generation are perceived correctly and comfortable without being damaged. There are guiding standards and publications published by international organizations to balance 
the exhibition and preservation requirements. The cultural property exhibited in museums are classified by International Commission on Illumination (CIE) and European Committee for Standardization (CEN) in four category as insensitive, low sensitivity, medium sensitivity, and high sensitivity in terms of light sensitivity classification and limiting illuminance, annual exposure time, and upper limit of annual luminous exposure are determined for each category (CIE, 2004; CEN, 2014). The average illuminance and illuminance uniformity values for various areas, tasks or activities are provided in the European Standard EN 12464-1 (2011). The possible contrasts between the exhibited artwork and its vertical background are divided into three separate groups as 1:1, 3:1, and 10: 1 in the European Standard EN 16163 (2014). Feltrin et al. (2017) and Wilson (2006) investigated the impact of the background colour on the appearance of the exhibits. Information on the ultraviolet radiation content of various light sources, which should be taken into consideration in lamp selection, is found in the literature (CIE, 2004; IESNA, 1996). In the literature there is also information on the choice of colour temperature of the lamp to be used for museum lighting (CIE, 2004). Various studies have been performed to determine the preference of the subjects about the perceived appearance of objects at different colour temperatures (Feltrin et al., 2017; Csuti et al., 2015; Garside et al., 2017; Luo et al., 2016; Vidovszky- Németh \& Kosztyán, 2016; Scuello et al., 2004). Kılıç (1985) suggests that the exhibition rooms in a museum building should be designed to allow visitors to walk starting from the rooms with lowest illuminance and finishing at the end with the rooms of highest illuminance. The necessity to prevent glare (Druzik \& Michalski, 2011) or glare by reflection (Wilson, 2006) is pointed out in the previous studies. The literature also includes precautions that can be taken to avoid direct glare and glare by reflection in display halls (CEN, 2014; IESNA, 1996). International Council of Museums recommends $15^{\circ}-25^{\circ} \mathrm{C}$ temperature and $50 \%$ relative humidity as set point or annual average in general museums and art galleries (ICOM, 2004). Great importance is attached also to energy consumption in museum lighting and advantages of LED lighting compared to traditional light sources are emphasized (Csuti, et al., 2015; Garside et al, 2017; Druzik \& Michalski, 2011).

Although there are numerous publications which offer guidance on how to illuminate museums, the way in which the illuminance and uniformity on three-dimensional sensitive artefacts are controlled by museum professionals is not documented. A recommended uniformity value with regard to the illuminance distribution on two or three dimensional artefacts could not be 
found in literature. Particular attention in lighting control deserves the case when 3D objects of different dimensions and sensitivity categories are placed side by side. Another theme that is not particularly highlighted in museum lighting is the shadows that play a role in perceiving the properties of objects such as form and texture. Although the importance of controlling direct glare is emphasized, the limiting values for the general lighting of the exhibition hall as well as for the showcase lighting are not specified in the literature. While precautions of reflected glare caused by windows in the daylit rooms are provided in literature, information to prevent veiling reflections of luminaires or illuminated showcases are insufficient. Three main factors to be taken into consideration in museum lighting are the preservation of artworks, the visitor's perfect perception, and energy efficiency. If the conversion of a historical building into museum is the case or the museum building has a remarkable architecture, the perceptibility of the exhibition hall itself can be considered as a fourth factor that should be considered in lighting. When it is impossible to achieve the aimed conditions for all four factors entirely, making an order of precedence is a rational approach. The need to compromise on the preservation and good perception of works of art is often emphasized in the literature. A compromise is an agreement reached by mutual concessions of conflicting claims. Concession from conservation requirements can not be accepted if we consider artworks as borrowed from the next generation and not just as our cultural heritage to the future. In this context, the preservation of artworks should come first; the visual comfort of visitors should rank second. According to the historical and artistic characteristics of the exhibition hall, the third rank should be assigned to either the energy consumption or the perceptibility of the hall.

There is a number of lighting design criteria involved in the comfortable and accurate perception of objects, and the required conditions for all of these criteria may not be obtained in a lighting arrangement. How should be the priority ranking among the criteria to be considered in the museum lighting? In addition to the lighting design decisions, are there other factors that are determinant in generating appropriate conditions for all criteria? The aim of this study is;

- to develop proposals for the missing guidelines in museum lighting,

- to present an approach to evaluate different lighting alternatives in terms of conservation, perception of artworks precisely, and energy efficiency,

- to design different lighting alternatives for the exhibition hall of a museum, and to classify these lighting design 
alternatives according to the presented approach with regard to the preservation of works of art, the visual comfort of visitors, the energy consumption, and the perceptibility of the exhibition hall.

It was decided to conduct this study on an existing museum and Museum of Palace Collections was selected (Çelikmez, 2017). In order to introduce the approach to the evaluation of lighting alternatives of a museum, first the features of the examined exhibition hall, the designed lighting alternatives and their investigation with respect to lighting design criteria are explained.

\section{FEATURES OF THE EXHIBITION HALL}

The ground floor of the Museum of Palace Collections located in Istanbul consists of the art gallery displaying temporary exhibitions, the permanent exhibition hall and the depot. The permanent exhibition hall displaying objects used in the last period Ottoman palaces is handled in this study. The load bearing structure of the exhibition space consists of stone masonry. The hall with an area of $1100 \mathrm{~m}^{2}$ has a plastic-based floor coating. The great part of the hall has a hipped-gable roof whereas a small part is covered by a dome roof. The wooden structure bearing the roof is dark brown. The height of the space is $8.00 \mathrm{~m}$ under the hipped-gable roof and $6.30 \mathrm{~m}$ under the dome roof. Window openings and skylights in the dome roof are covered with a dark panel, preventing the daylight penetration. Plan and section of the exhibition hall are given in Figure 1. The photographs in Figure 2 show the general appearance of the hall, the view directions of the photographs are shown on the plan in Figure 1. As of August 19, 2018, the Museum of Palace Collections displays, as listed on its website, inter alia, palace child's dresses, furniture, calligraphy art and writing sets, porcelain, embroidered artworks, lighting, heating, health and industrial tools, paintings, watches, music instruments, crystal, porcelain, silver sets of table, crystal offering sets, toys, and books. The exhibits are displayed to a great extent in closed wallor freestanding showcases (28 pieces). Seventeen wall showcases with one glass surface are located either leaning against the wall or in pairs leaning against each other. Showcases with two glass surfaces ( 2 pieces), three glass surfaces ( 4 pieces), and four glass surfaces (5 pieces) are located freestanding in the exhibition hall. The objects in the back part of the hall near the depot are displayed behind a glass partition. Additionally are freestanding displays on five platforms in the hall. 

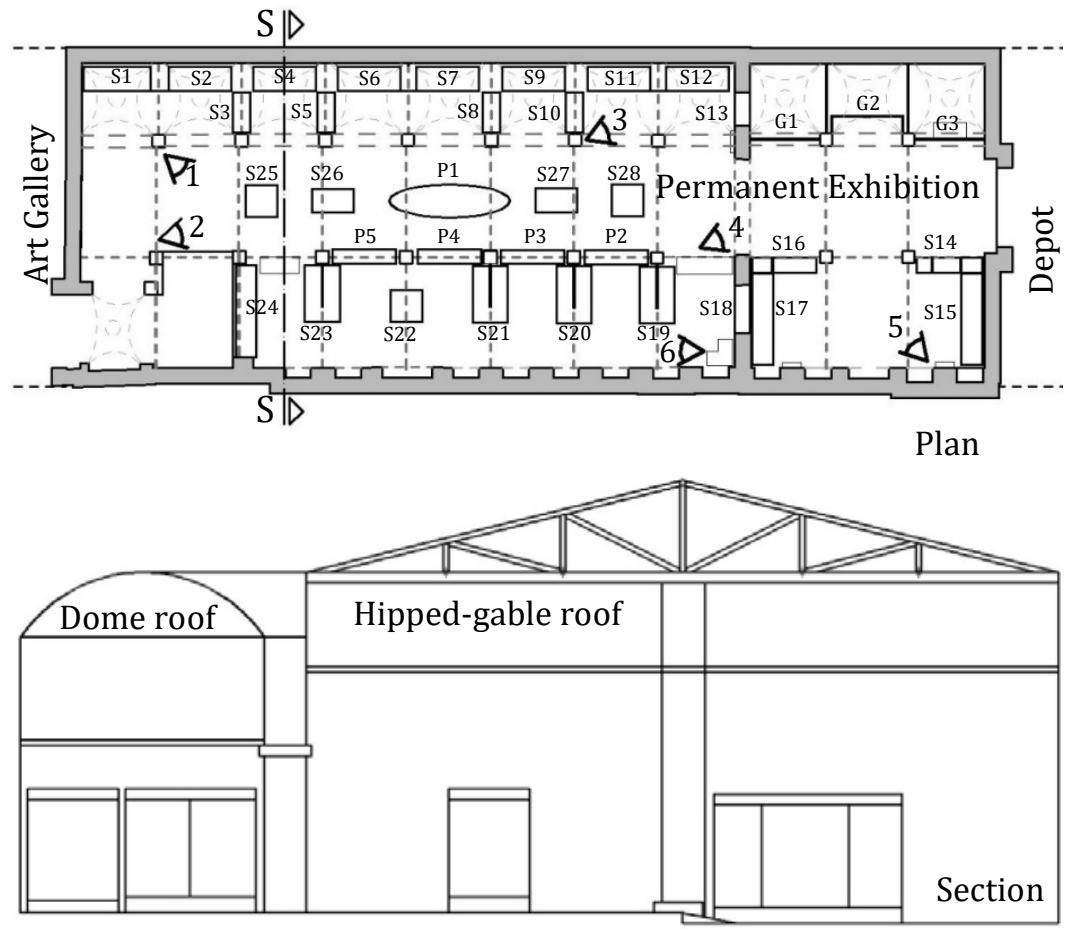

Figure 1. Plan and section of the Museum of Palace Collections

S: showcase, P: platform, G: glass partition, 1-6: viewpoints

Figure 2. Views of permanent exhibition from six various directions
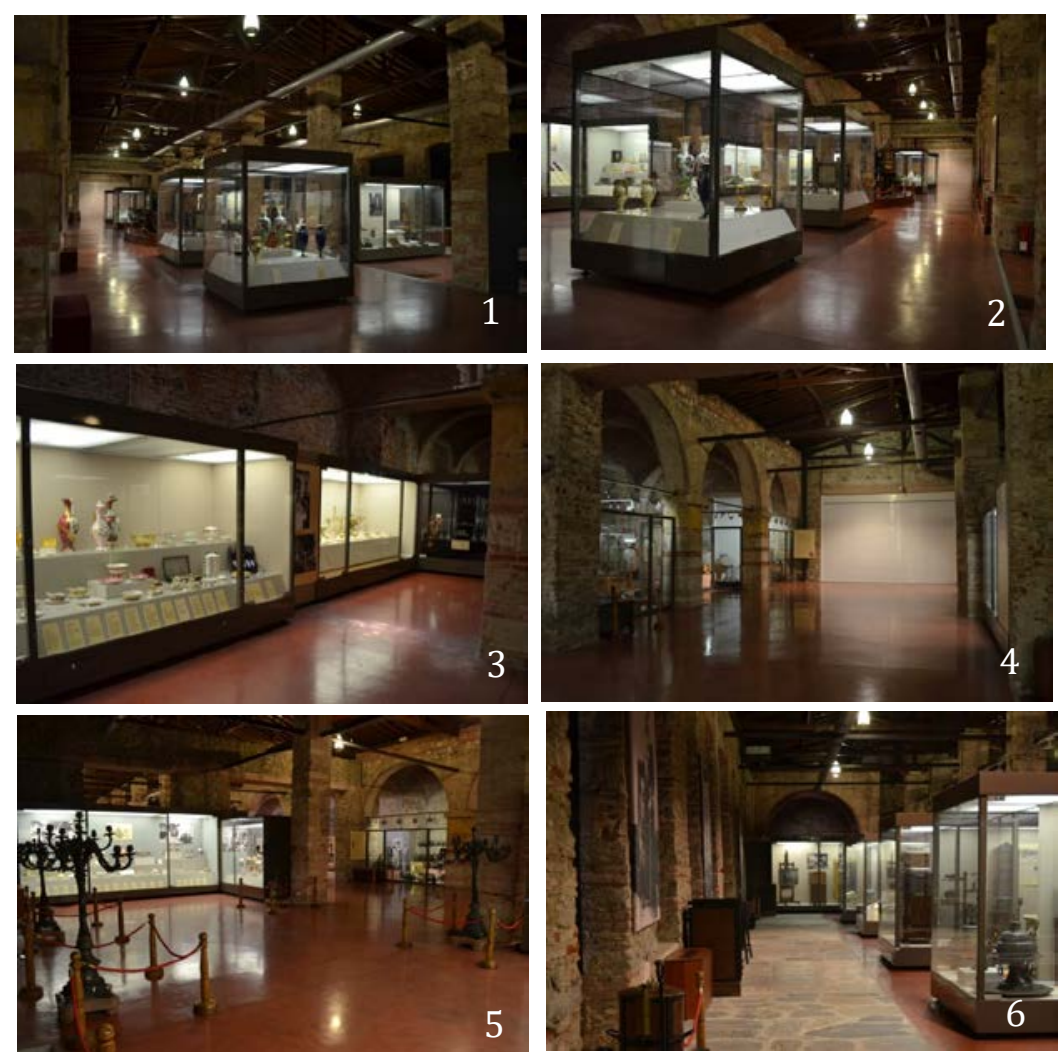
An Approach to Evaluate Exhibition Lighting Alternatives: The Case of Museum of Palace Collections

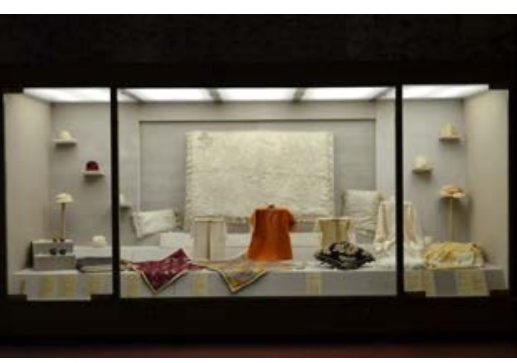

Showcase with one glass surface

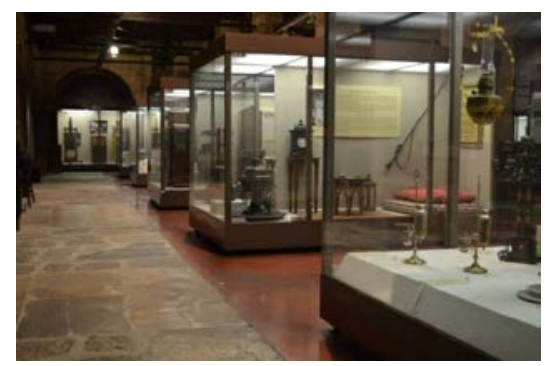

Showcase with three glass surfaces

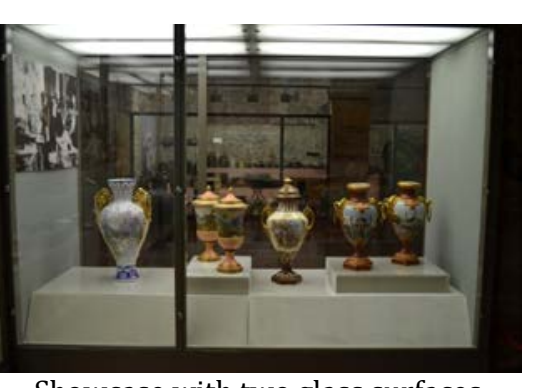

Showcase with two glass surfaces

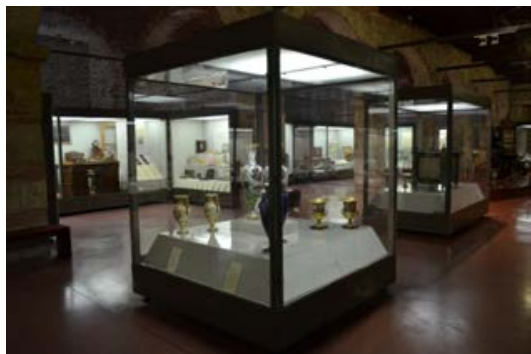

Showcase with four glass surfaces

\section{DESIGN OF LIGHTING ALTERNATIVES}

Different lighting alternatives to be applied in the exhibition hall are investigated. The existing showcases, furnishings and exhibition order in the hall are kept constant in order to limit the scope of the study. The lighting arrangement alternatives, aimed to reveal possible different results in terms of preservation of artefacts, visitors' comfortable perception, energy consumption, and perceptibility of the exhibition hall consist of general lighting, dome lighting, and showcase lighting. Three alternatives for general lighting $(1,2,3)$, four alternatives for showcase lighting $(A, B, C, D)$, and one alternative for dome lighting were created. Lighting alternatives were modelled by the DIALux lighting program. Using AutoCAD drawings, on-site observation and measurements, taken photographs, it is ensured that the model hall reflects as accurate as possible the real hall. The properties of the dome lighting are the same in all alternatives. The same luminaire and lamps have been assigned in all three general lighting alternatives. Similarly, the linear lamp used in three showcase alternatives was the same. Although the intent was to use only LED lamps, fluorescent lamps were used for general lighting because the required light intensity distribution could not be found among LED equipped luminaires.

\section{General Lighting}

The decision on the type and location of the appropriate luminaire for general lighting was made taking into consideration the architectural and structural characteristics of the exhibition room and the display order. Large floor and the associated large circulation area, freestanding displays on the platforms, metal bars between the columns were the data that

Figure 3. Examples of showcases in the exhibition hall 
influenced the basic design decisions. The luminaires are fixed to the existing metal bars between the columns. The same linear luminaire was used in all three lighting alternatives for general lighting, with the difference between the alternatives being the type of lighting. These alternatives are direct lighting (General lighting alternative 1), indirect-direct lighting (General lighting alternative 2) and indirect lighting (General lighting alternative $3)$. As known, direct lighting is the most economic choice, while indirect lighting is the most expensive in terms of energy efficiency. Moreover, as light coloured as possible and matte ceiling is required when applying indirect-direct or indirect lighting types. However, the economic aspect should not be necessarily put in the first place when it comes to the perfect perception of the displayed objects and the interior of a historical building converted into museum. The increase of energy consumption should be kept in mind when regarding indirect-direct and indirect lighting as general lighting choices in a space with a high and dark ceiling. On the other hand, it will be useful to reveal the effect of these lighting types on visual comfort. It is sufficient to be aware that visual comfort can be achieved with less energy consumption, when the interior surfaces, especially the ceiling, are light coloured. The luminaires are mounted under, over and under, and over the metal bars for direct, indirect-direct, and indirect lighting, respectively (Figure 4). The position of the luminaires on the metal bars is appointed with regard to the furniture.

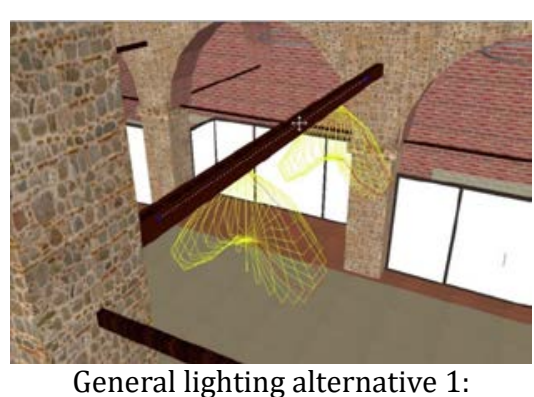

General lighting alternative 1: Direct lighting

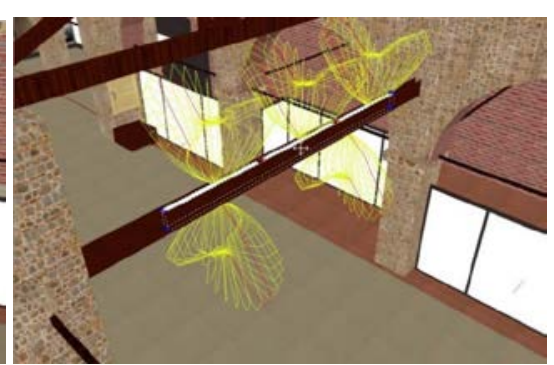

General lighting alternative 2: Indirect-direct lighting
Figure 4. Luminaire position for general lighting alternatives

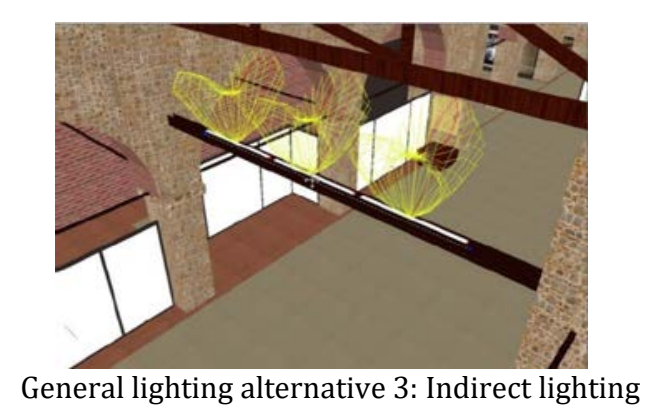




\section{Dome Lighting}

Approximately one-third of the ceiling is composed of domes and the dome ceilings are emphasized by indirect lighting. The contribution of reflected light from the dome ceiling to the general lighting is also aimed by indirect lighting. Ring shaped luminaires, suspended from the centre of each dome, are used and the height of the luminaires is kept in the height of the metal bars in the hall (Figure 5).
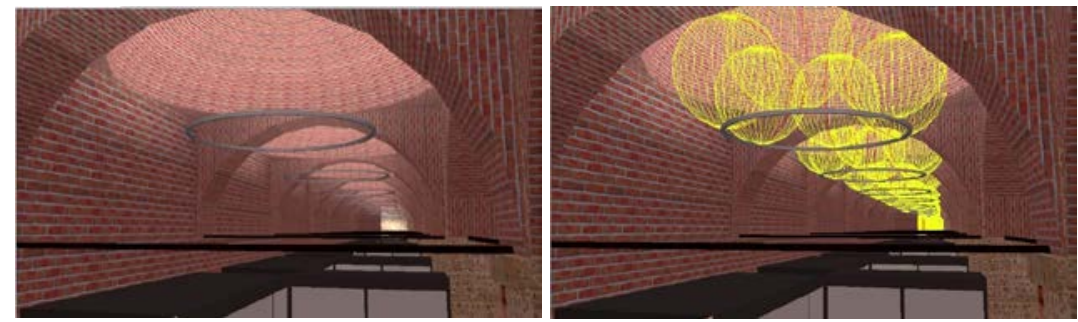

Three domes above the artworks exhibited behind the glass partitions (Figure 1; G1, G2, G3) are illuminated by indirectdirect lighting, so that the visibility of the dome surfaces are ensured and the objects underneath are illuminated. The features of the luminaires used here are similar to those luminaires illuminating the other domes indirectly; the difference between them is just the lighting type (Figure 6). Ring shaped luminaires with indirect-direct lighting are also used in the entrance section of the exhibition hall to meet the need for general lighting in this area. The lighting arrangement related to the display behind the glass partitions, the entrance, and the domes throughout in the hall are the same in all lighting alternatives.
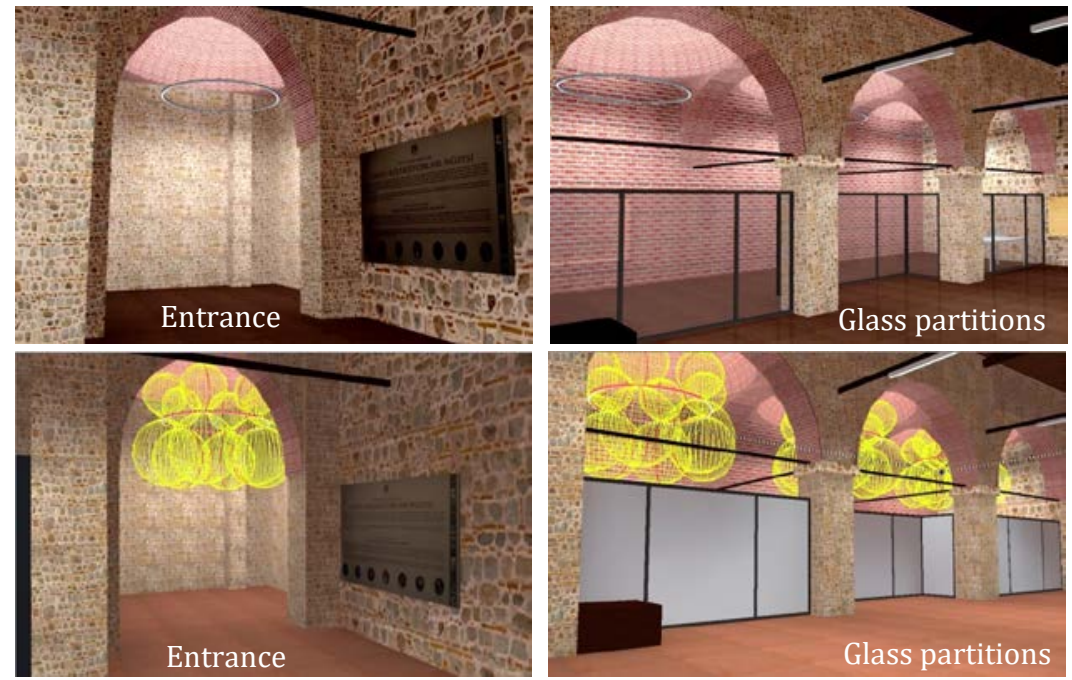

Figure 5. Dome lighting

Figure 6. Lighting of the entrance section and the glass partition zones 


\section{Showcase Lighting}

Lighting the showcases from inside is considered as the most appropriate attitude taking into account the showcase types and their location in the hall. Four alternatives are established for showcase lighting:

- Alternative A: Linear lamps fixed horizontally on the showcase ceiling and covered by an opal glass (Figure 7a).

- Alternative B: Linear luminaire fixed vertically behind the metal profiles at the front glass surface of the showcase (Figure 7a). This alternative has not been applied to freestanding showcases with two, three, or four glass surfaces, but to the showcases leaning against the walls. Because, linear lamps can be hidden behind the vertical profiles in showcases with one glass surface and kept out of the visual field, while being in the observers' field of view in other types of showcases. Accordingly, 16 showcases with one glass surface were illuminated according to Alternative B described; other showcase types were illuminated according to Alternative A.

- Alternative C: Linear luminaire fixed horizontally behind the metal profiles at the junction of the front glass and the showcase ceiling (Figure 7b). This alternative could not been applied in the freestanding showcases due to the same reason explained for Alternative B. Therefore, 18 showcases with one glass surface were illuminated according to Alternative $\mathrm{C}$, lighting of other showcases were conducted according to Alternative A.

- Alternative D: Small luminaires fixed at certain intervals behind the metal profiles at the junction of the front glass and the showcase ceiling (Figure 7b). The implementation of this alternative is similar to Alternative C. Alternative D could not been applied in the freestanding showcases due to the same reason explained for Alternatives B and C. Eighteen showcases with one glass surface were illuminated according to Alternative D, lighting of other showcases were performed according to Alternative A.

Figure 7a. Showcase lighting alternatives

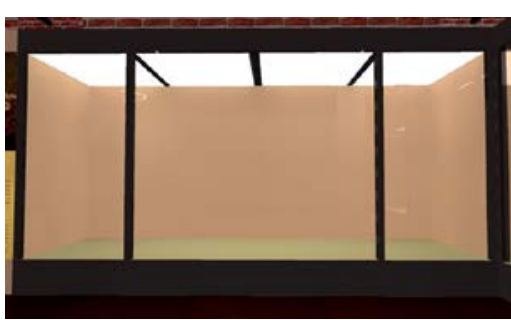

Alternative A: Horizontal linear lamp behind the opal glass

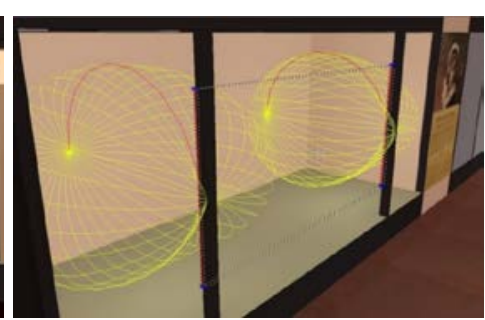

Alternative B: Vertical linear luminaire behind the metal profile 


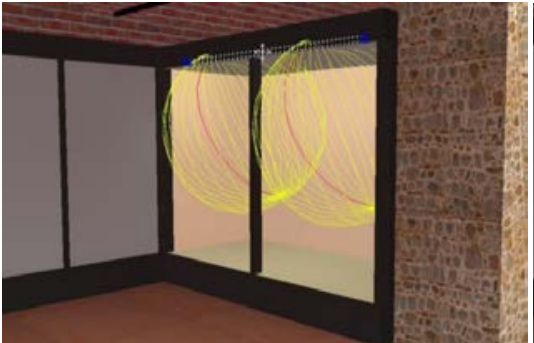

Alternative C: Horizontal linear luminaire behind the upper metal profile

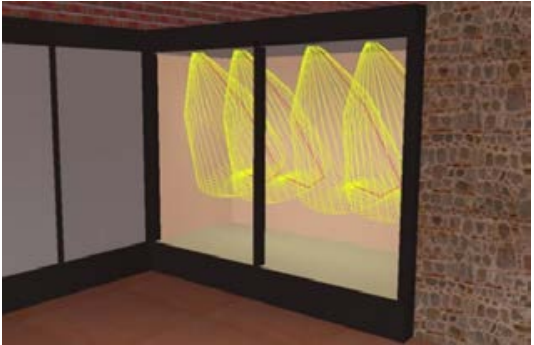

Alternative D: Small luminaire behind the upper metal profile

\section{Lighting Arrangement Alternatives}

Twelve different lighting arrangements (LA) were produced as a result of the combination of three general lighting and four showcase lighting alternatives (Table 1). The appearance of the simulated exhibition hall as a whole differs mainly upon to the general lighting alternatives and the showcases do not contribute much to the appearance of the hall in this scale. Therefore, three lighting arrangement examples are submitted in Figure 8 representing 'direct', 'indirect-direct', and 'indirect' general lighting alternative.

Table 1. Properties of luminaires in the exhibition hall

\begin{tabular}{|c|c|c|c|}
\hline \multicolumn{2}{|c|}{$\begin{array}{l}\text { Lighting } \\
\text { arrangement } \\
\text { (LA) }\end{array}$} & \multirow{2}{*}{$\begin{array}{l}\text { Symbol-Type } \\
\text { for general } \\
\text { lighting }\end{array}$} & \multirow[t]{2}{*}{ Symbol-Type for showcase lighting } \\
\hline No. & Symbol & & \\
\hline 1 & $1 \mathrm{~A}$ & 1-Direct lighting & $\begin{array}{l}\text { A-Horizontal linear lamp behind the } \\
\text { opal glass }\end{array}$ \\
\hline 2 & $2 \mathrm{~A}$ & $\begin{array}{l}\text { 2-Indirect-direct } \\
\text { lighting }\end{array}$ & $\begin{array}{l}\text { A-Horizontal linear lamp behind the } \\
\text { opal glass }\end{array}$ \\
\hline 3 & $3 \mathrm{~A}$ & $\begin{array}{l}\text { 3-Indirect } \\
\text { lighting }\end{array}$ & $\begin{array}{l}\text { A-Horizontal linear lamp behind the } \\
\text { opal glass }\end{array}$ \\
\hline 4 & 1B & 1-Direct lighting & $\begin{array}{l}\text { B-Vertical linear luminaire behind the } \\
\text { metal profile }\end{array}$ \\
\hline 5 & $2 \mathrm{~B}$ & $\begin{array}{l}\text { 2-Indirect-direct } \\
\text { lighting }\end{array}$ & $\begin{array}{l}\text { B-Vertical linear luminaire behind the } \\
\text { metal profile }\end{array}$ \\
\hline 6 & $3 B$ & $\begin{array}{l}\text { 3-Indirect } \\
\text { lighting }\end{array}$ & $\begin{array}{l}\text { B-Vertical linear luminaire behind the } \\
\text { metal profile }\end{array}$ \\
\hline 7 & $1 \mathrm{C}$ & 1-Direct lighting & $\begin{array}{l}\text { C-Horizontal linear luminaire behind } \\
\text { the upper metal profile }\end{array}$ \\
\hline 8 & $2 \mathrm{C}$ & $\begin{array}{l}\text { 2-Indirect-direct } \\
\text { lighting }\end{array}$ & $\begin{array}{l}\text { C-Horizontal linear luminaire behind } \\
\text { the upper metal profile }\end{array}$ \\
\hline 9 & $3 \mathrm{C}$ & $\begin{array}{l}\text { 3-Indirect } \\
\text { lighting }\end{array}$ & $\begin{array}{l}\text { C-Horizontal linear luminaire behind } \\
\text { the upper metal profile }\end{array}$ \\
\hline 10 & 1D & 1-Direct lighting & $\begin{array}{l}\text { D-Small luminaire behind the upper } \\
\text { metal profile }\end{array}$ \\
\hline 11 & 2D & $\begin{array}{l}\text { 2-Indirect-direct } \\
\text { lighting }\end{array}$ & $\begin{array}{l}\text { D-Small luminaire behind the upper } \\
\text { metal profile }\end{array}$ \\
\hline 12 & 3D & $\begin{array}{l}\text { 3-Indirect } \\
\text { lighting }\end{array}$ & $\begin{array}{l}\text { D-Small luminaire behind the upper } \\
\text { metal profile }\end{array}$ \\
\hline
\end{tabular}

Figure 7b. Showcase lighting alternatives 
Figure 8. Examples of lighting alternatives in the modelled hall

Lighting arrangement 1 (1A):

1: Direct lighting

A: Horizontal linear lamp behind the opal glass

Lighting arrangement 5 (2B):

2: Indirect-direct lighting

B: Vertical linear luminaire behind the metal profile

Lighting arrangement 12 (3D):

3: Indirect lighting

D: Small luminaire behind the upper metal profile

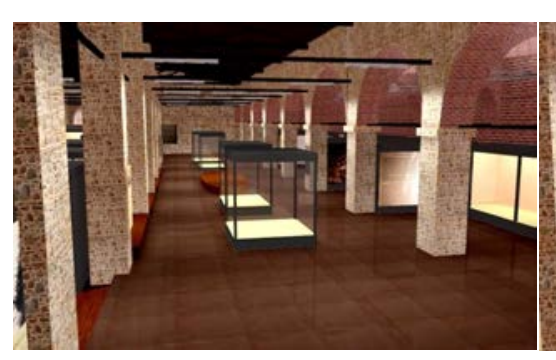

Lighting arrangement $1(1 \mathrm{~A})$

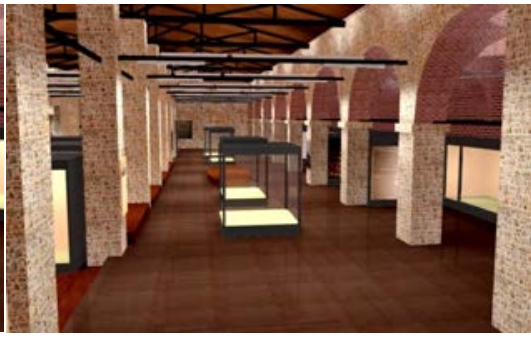

Lighting arrangement 5 (2B)

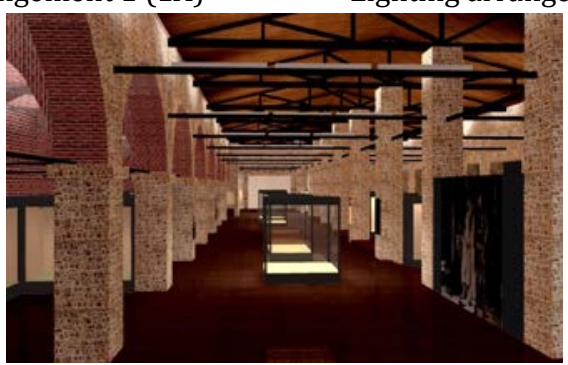

Lighting arrangement 12 (3D)

\section{COMPARISON OF THE LIGHTING ARRANGEMENT ALTERNATIVES}

The comparison of the results obtained in twelve lighting arrangement alternatives was conducted for general-, showcase-, platform-, and glass partition zone lighting in terms of illuminance and illuminance uniformity, direct glare, glare by reflection, shadow attributes, and energy consumption.

\section{Illuminance and Uniformity of Illuminance}

Since no reference to the illuminance uniformity $\left(U_{0}=E_{\min } / \bar{E}_{\mathrm{m}}\right)$ was found in the literature for museum lighting, EN 12464-1 standard was referred to and the highest value among recommended uniformities for various activities, that is 0.7 , was considered as reference value for exhibits $\left(U_{0} \geq 0.7\right)$.

General lighting: No reference to the illuminance and uniformity related to the circulation area around the exhibits was found in the literature. Therefore, traffic zones inside buildings in EN 12464-1 was referred to and the values for circulation areas as $\bar{E}_{\mathrm{m}} \geq 100 \mathrm{~lx}$ and $U_{0} \geq 0.40$ appropriated under the circumstance that the targeted illuminance and uniformity on the exhibits are not negatively affected. The average illuminance was below 100 $\mathrm{lx}$ for indirect general lighting (LA-3, LA-6, LA-9, LA-12) whereas this value was ensured for the other general lighting alternatives. As expected the most uniform illuminance was acquired at indirect general lighting, followed by indirect-direct and direct lighting (LA-1, LA-4, LA-7, LA-10).

Dome lighting: The illuminance on the inner surface of the domes could not be calculated by means of the lighting program. Because, the domes are constituted by bringing together a number of small plane segments and it is very difficult if not impossible to assign each segment to the related dome and to 
define the size of lots of segments. Another limitation is that curved calculation surfaces (CS) are non-producible in the lighting program. Due to this, the illuminance and uniformity on the dome surface could not be calculated, so an approximate assessment was made by means of the false colour rendering property of the program. The fairly uniform illuminance on the inner surfaces of the domes was about $100 \mathrm{~lx}$ at all lighting alternatives, which enabled the perception of its architectural features comfortably and accurately (Figure 9).
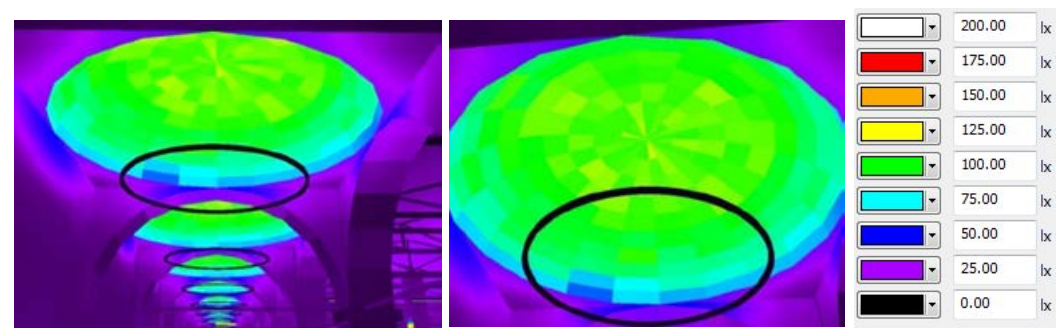

Showcase lighting: Artefacts are illuminated by taking into consideration their features such as size, shape, position, and light sensitivity category. When lighting two-dimensional objects, such as pictures, graphics, maps, mounted on a wall or a vertical display panel, it is sufficient to provide the required uniformity of illuminance on the exhibition area and to ensure the maximum illuminance in this area is lower than the allowed limit value. Uniform illuminance distribution on the display surface does not alter the original luminance contrasts of artworks. In contrast, non-uniformity in illuminance would cause the lightness-darkness of colours is perceived differently from the original coloration of artworks. This may lead visitors to interpret the exhibits differently than intended. As specified below, there are additionally issues to consider when illuminating three-dimensional objects such as sculptures, vases, and costumes:

- Two-dimensional objects are displayed on plane surfaces, and the evenly distributed illuminance on plane surfaces is mainly related to the selection of the appropriate luminaire and its positioning. Successful results can also be achieved by direct lighting consuming the least amount of energy compared with the other lighting types. It is more difficult to ensure uniform illuminance on the surface of threedimensional objects, and the main requirements for this are light coloured interior surfaces and indirect lighting.

- Display surfaces for two-dimensional objects may be predominantly vertical, but horizontal or inclined surfaces are also common. Depending on the position of the display surface, the illuminance on a vertical, horizontal or inclined
Figure 9. Illuminance uniformity on the dome surface 
calculation surface is determined. For three-dimensional objects, cylindrical or semi-cylindrical illuminance as well as vertical, horizontal or inclined illuminance can be calculated according to the properties and position of the object and the view direction to the object.

- When organizing an exhibition in a museum, periods and/or people may be targeted in grouping of objects. Another approach in grouping is considering the various properties and place of use of the objects. A further approach to the grouping is the light sensitivity category of the objects. Where a group includes objects of different sensitivity categories, limiting illuminance and annual exposure time should be defined considering objects of highest sensitivity. Two dimensional objects of different sizes can be put side by side on the vertical, horizontal or inclined display panel and it is easy to ensure the required uniformity of illuminance along the panel. If three dimensional objects of different sizes and shapes are displayed together, it should be decided on which calculation plane the required illuminance should be provided. For example, if insensitive and small objects are displayed on the floor of a showcase, the required illuminance and uniformity can be produced on the floor of the showcase. If the objects in question are of high sensitivity, the illuminance calculation surface should be at a distance parallel to the bottom of the showcase that covers all underlying objects. If additionally large objects are displayed in the same showcase, calculation surfaces should be defined in accordance with their sizes and locations to control the provided illuminance. If the objects are of the sensitivity category low, medium or high, calculation surfaces should be positioned in front of the objects. For objects of the insensitive category, an average position for the calculation surface can be determined by leaving half of the object behind and the rest in front of the surface.

Depending on these explanations, each showcase was considered separately and the calculation surfaces were determined horizontally, inclined or vertically according to the properties of the objects. The average- and maximum illuminance and the uniformity of illuminance on the defined calculation surfaces were calculated. It was aimed not to exceed the maximum illuminances (for category 3, medium sensitivity: $E_{\max } \leq 50 \mathrm{~lx}$; for category 2, low sensitivity: $E_{\max } \leq 200 \mathrm{~lx}$ ) allowed according to the sensitivity category of the objects (CIE, 2004; CEN, 2014). The calculation surfaces (CS) defined for three showcases are shown as examples in Figure 10 as the simulation by the lighting program (right) and the visualization on the photographs (left). 
Each calculation surface in a showcase is stated by a different colour.

Targeted illuminances and uniformity on a total of 120 calculation surfaces defined in 28 showcases were obtained in all lighting alternatives to a great extent. The upper illuminance limit for sensitive objects exceeded a little on a small number of calculation surfaces in showcases numbered 20,22, 23, which are located in the middle of the hall and have three or four glass surfaces. Hence, the interreflected light and light from other showcases penetrate these showcases. Some precautions can be taken to control the illuminance like to shorten the annual exposure time, relocate these showcases or put partitions between them. On some of the calculation surfaces in showcases 14 and 15, the limit illuminance exceeded in the showcase lighting alternatives $\mathrm{C}$ and $\mathrm{D}$. The reason for this is that the top of large objects is very close to the showcase ceiling and consequently to the lamps. For these, showcase lighting alternatives $\mathrm{C}$ and $\mathrm{D}$ should not be applied or the annual exposure time should be shortened. For objects of low sensitivity, the limit value of $200 \mathrm{~lx}$ was not exceeded on any calculation surface. The uniformity of illuminance was $0.60 \leq$ $U_{0}<0.70$ in most showcases and $0.50 \leq U_{0}<0.60$ in a significant number of showcases. The uniformity was below 0.50 in a small number of showcases. The most unfavourable results in terms of illuminance distribution have emerged in showcase alternative D, which was followed by B and C.

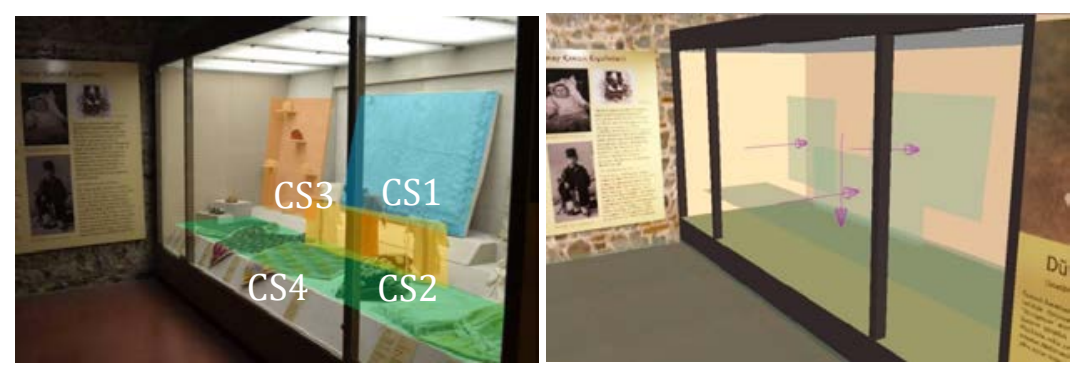

Showcase no. 1

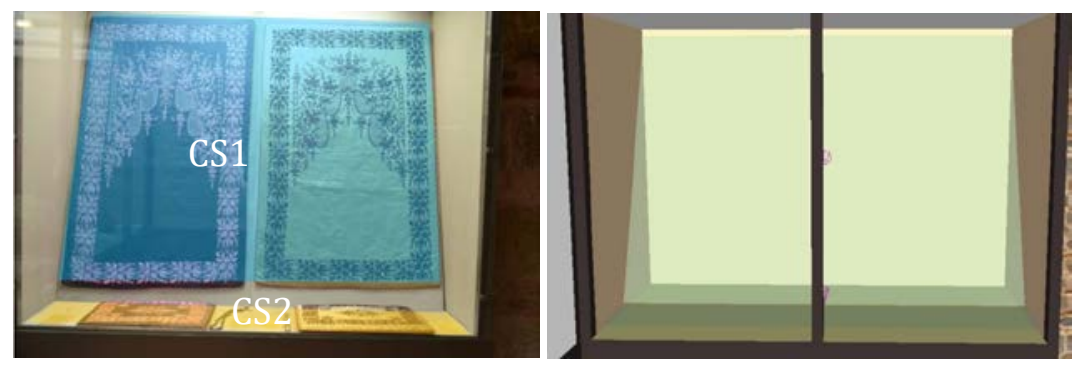

Showcase no. 10
Figure 10a. Calculation surfaces for some showcases 
Figure 10b. Calculation surfaces for some showcases

Figure 11. Calculation surface for platform 1

Figure 12. Calculation surfaces for glass partition zone 2

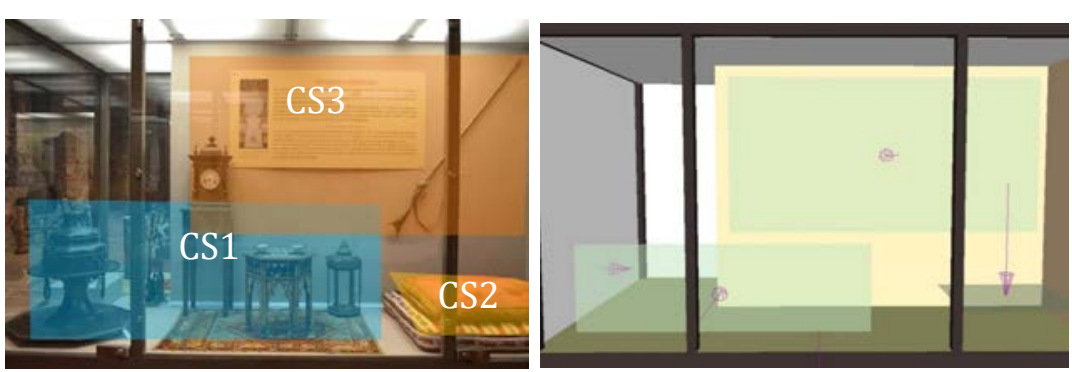

Showcase no. 20

Platform lighting: The minimum, maximum, average illuminances and uniformities on the calculation surfaces assigned to the objects displayed on the platforms were calculated. For low sensitive wooden objects exhibited here, a maximum illuminance of $200 \mathrm{~lx}$ (sensitivity category 2) was targeted; for metal objects, no limitation was imposed on the illuminance (sensitivity category 1 ). For one of the platforms, the calculation surfaces defined in the model room and visualised on the corresponding photograph is shown as an example in Figure 11. The maximum illuminance regarding to low sensitivity objects was under $200 \mathrm{~lx}$. The targeted value in terms of illuminance uniformity has been ensured completely when indirect lighting was the case and to a great extent when the other lighting types were applied.
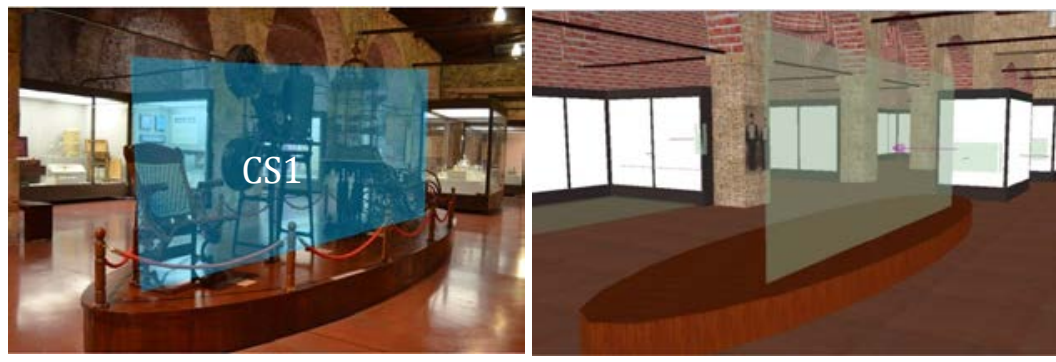

Glass partition zone lighting: Insensitive objects are displayed behind three glass partitions. One of the groups of artworks exhibited behind the glass partition is shown in Figure 12. The acquired results related to illuminance and uniformity are the same with the platform lighting.
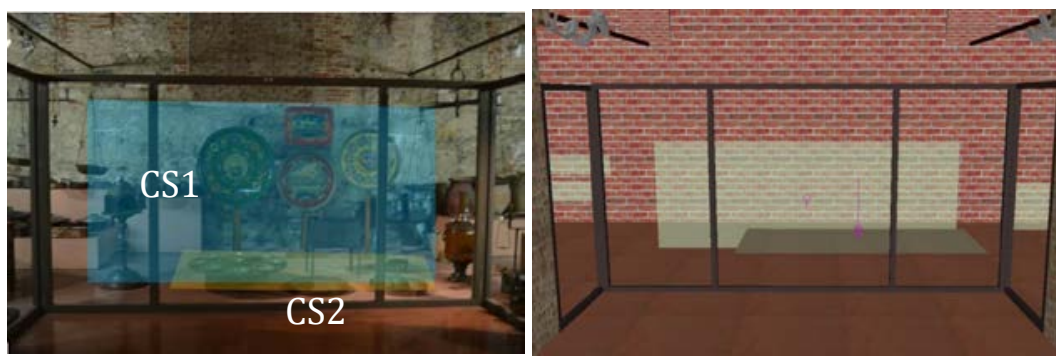


\section{Direct Glare}

The indirect-direct and direct general lighting alternatives have been investigated in terms of direct glare. For this purpose, $U G R_{\mathrm{L}}$ calculations were performed at various points in the circulation area and at observation points of showcases where general lighting luminaires could be in the visitor's field of view. The highest calculated values were 22 and 21 for Lighting Arrangement 1 and 2, respectively. Because the limiting value for the general lighting of exhibition halls is not specified in the literature, the recommended limit value of 28 for circulation areas and corridors in EN 12464-1 is considered for evaluation. These values below 28 show that general lighting will not lead to direct glare. It has been also ascertained that dome, platform, and glass partition zone lighting do not cause direct glare. Direct glare analyse was conducted for showcases of different length and height related to Alternative A. The approach in glare analyse is shown on a typical showcase section representing the majority of showcases (Figure 13). There are guiding values in the literature in terms of the average view distance to the vertical display surface (IESNA, 1996; IESNA, 2000; FGL, 2018). On the other hand, it is obvious that the distance required will vary depending on the dimension and position of the objects displayed in the showcase. An average distance of $50 \mathrm{~cm}$ from the glass surface of a showcase was judged appropriate by in-situ observations in order to perceive the features of the displayed object comfortable. IESNA suggests an eye height of $155 \mathrm{~cm}$ from the floor considering the average human height (IESNA, 1996; IESNA, 2000). The $U G R_{\mathrm{L}}$ value was 17 for the observer standing $50 \mathrm{~cm}$ away from the glass surface of a showcase. An $U G R_{\mathrm{L}}$ limit value, which should not be exceeded in museums, has not been found in the literature. Limit $U G R_{\mathrm{L}}$ values in the European Standard EN 12464-1 are specified as 19 for art rooms, offices, and several working conditions, 16 for colour inspections, technical drawings, manufacture of jewellery, etc. Taking into account these values, $U G R_{\mathrm{L}} \leq 19$ can be accepted for showcase lighting. Under this assumption, it can be concluded that the observer will not be affected by direct glare.

In the case of showcase lighting alternatives B, C and D, where the luminaires are arranged behind metal profiles, no direct glare occurs. The $U G R_{\mathrm{L}}$ values for these showcases have varied between 0 and 11 for different viewing directions. 
Figure 13. Investigation of showcase lighting according to direct glare

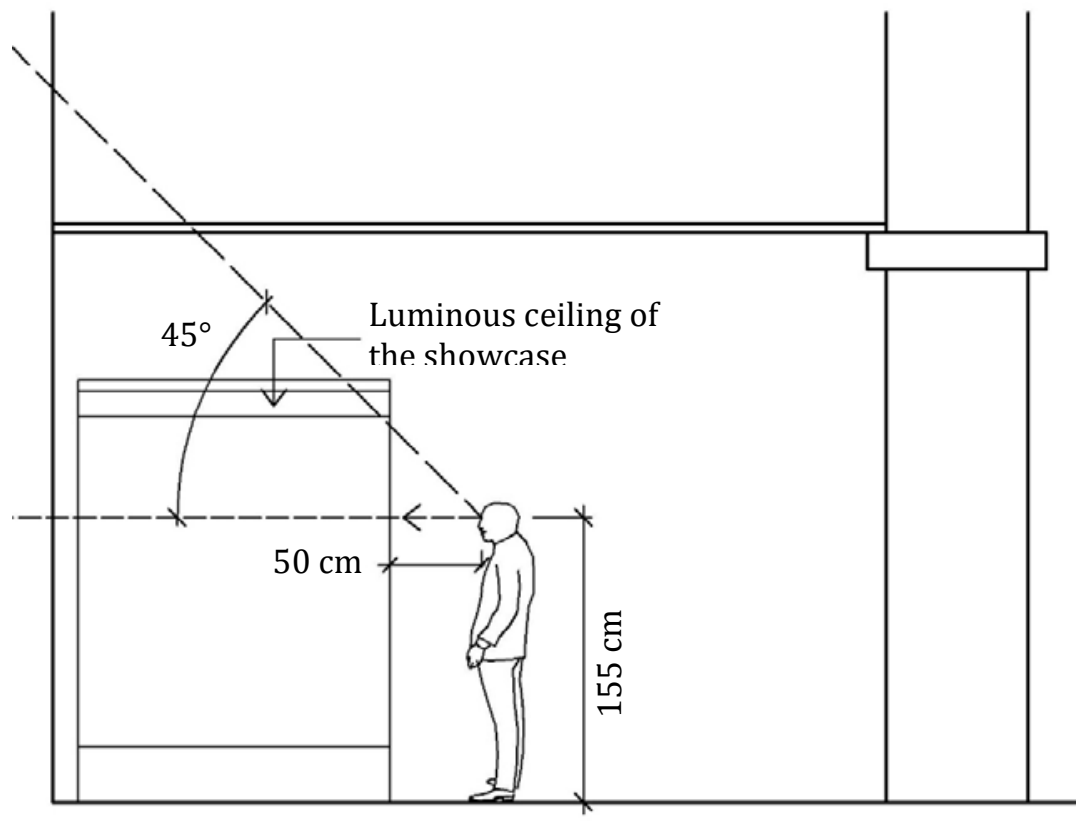

\section{Glare by Reflection}

The showcases are positioned opposite or perpendicular to each other in the exhibition room. Accordingly, the luminous ceiling of other showcases will cause reflected glare on glass surfaces of showcases lit according alternative A as shown in Figure 14. Apparent from Figure 14, the showcase 19 (S19) is in the reflection area of showcase 18 and the visitor observing the showcase 18 perceives the reflected image of showcase 19 and its luminous ceiling. The luminous ceiling of the S19, which is below the viewing angle of $45^{\circ}$, may make it difficult to perceive the artefacts. Measures such as using anti-reflection coatings on showcase glass surfaces, repositioning of showcases to avoid each other's reflection areas or putting partitions between them can be taken to avoid reflected glare.

On the glass surfaces of showcases lit according to alternatives B, $C$, and D, only the reflected images of other showcases' structure may be perceived, while the luminaires within them would not be in the viewing area. The reflected images of the outer surfaces of some luminaires, but not their openings used for general lighting and dome lighting, can be perceived on glass surfaces of some showcases that do not degrade the perception of the displayed objects. 


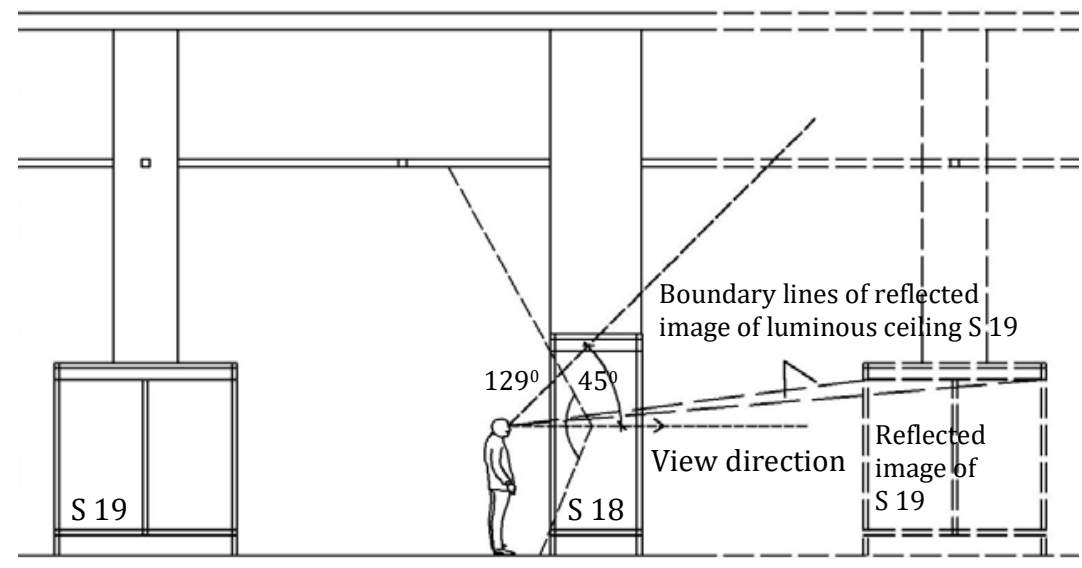

\section{Shadow Attributes}

Showcase lighting alternatives have been examined in terms of the effects of the self- and cast shadows of the artefacts on their visual perception. For this purpose, the showcase 7 (S7) was treated as an example (Figure 15) and the objects in the S7 were modelled in a simplified way (Figure 16).

The shadow properties of objects differ according to the lighting alternatives. Soft shadows, similar to those in the photograph of the showcase in Figure 15, are expected to be produced in Alternative A. However, due to the nature of the lighting software program, the visualization of soft shadows could not be good enough. In Alternative B, the cast shadows of objects clearly perceived on the floor and on the walls of the showcase are soft in one direction and harsh in the other direction due to the nature of the used linear lamps. The properties of cast shadows in Alternative $\mathrm{C}$ are similar to Alternative B. In this alternative, however, the shadows remain primarily behind the objects due to the position of luminaires and objects and therefore do not appear in the field of view. Harsh shadows created separately by each luminaire overlap partially, and as a result, multiple harsh shadows are perceived in Alternative D. Except for special circumstances, the preferred shadow features are 'soft and light' in every space. In this regard, it can be concluded that the shadow attributes are most positive in Alternative $\mathrm{A}$ and acceptable in Alternative C.

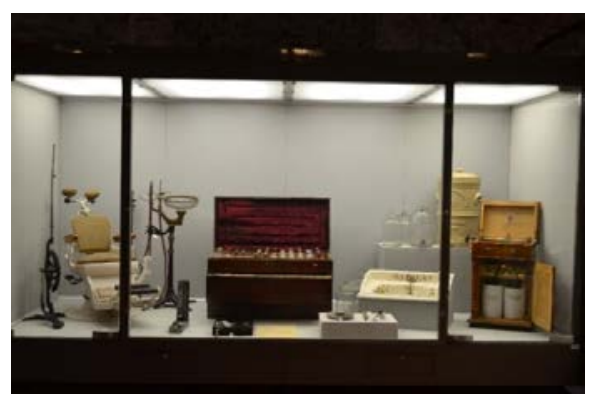

Figure 14. Reflected glare on the glass surface of a showcase caused by other showcases 
Figure 16. Comparison of showcase lighting alternatives in terms of shadow properties
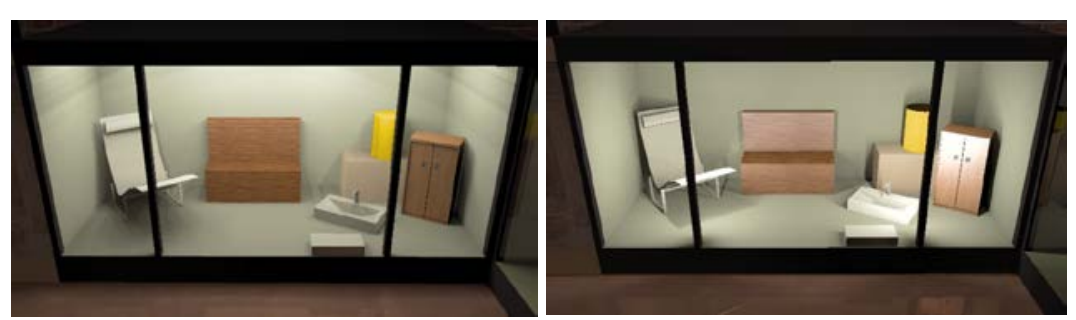

Lighting arrangement 3 (Alternative A) Lighting arrangement 6 (Alternative B)
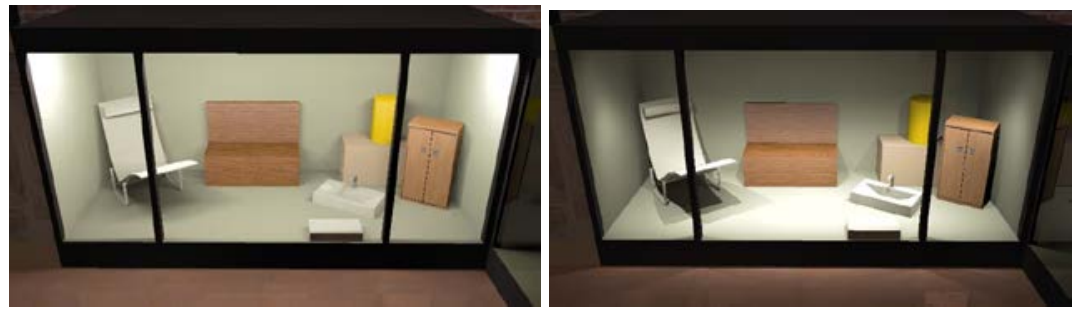

Lighting arrangement 9 (Alternative C) Lighting arrangement 12(Alternative D)

\section{Energy Consumption}

The twelve lighting arrangements discussed were compared in terms of energy consumption. As known, low energy consumption depends on both the luminous efficacy of the lamp and the luminaire efficiency. Factors such as the luminous intensity distribution and the location of the luminaire also play a role in energy consumption. It is impossible to consider numerous options for lamp and luminaire types for comparison purposes. Thus, the total luminous flux emitted by all the installed luminaires has been taken into account to avoid that the luminous efficacy of lamps and the light output ratio of luminaires play a role in this comparison. In this way, data is generated for comparison purposes only, without reference to a product available on the market. In practice, the luminous efficacy of the lamp and the luminaire efficiency, thus the total power consumed should be taken into account in comparison of alternatives. The effect of design decisions such as luminaire shape (small, linear), lighting type (direct, indirect, etc.), and luminaire position on energy consumption were evaluated whereby the same luminaires and lamps were used in all general lighting and showcase lighting alternatives. According to the calculations, the order of the lighting arrangements discussed was determined from the most expensive to the most economical as follows: LA-2, LA-8, LA-11, LA-5, LA-3, LA-9, LA-1, LA-12, LA6, LA-7, LA-10, LA-4. In other words, the amount of luminous flux emitted from all the luminaires installed was the most in 'indirect-direct general lighting and showcase lighting with horizontal linear lamp behind the opal glass (LA-2)' and the least in 'direct general lighting and showcase lighting with vertical linear luminaire behind the metal profile (LA-4)'. 
AN APPROACH FOR EVALUATING LIGHTING ARRANGEMENT ALTERNATIVES

In order to determine the most suitable lighting arrangement alternatives, it was examined to what extent the requirements according to the lighting design criteria in each alternative were met. For this purpose, for each lighting arrangement alternative, the illuminance and its distribution on the defined calculation surfaces were calculated with the DIALux program for general lighting, showcase, platform and glass partition zone lighting. In addition, detailed investigation was performed concerning direct glare and glare by reflection for each alternative. This examination was also carried out in terms of the shadow properties in the showcases and the overall perceptibility of the hall. Comprehensive calculation and study results could not be included in this article (Çelikmez, 2017). Considering the results of the detailed calculations and etudes for the regarded criteria, the lighting arrangement alternatives are classified in four grades as presented in Table 2 . The most positive results are stated with Grade 1. It is obvious that this classification applies to the studied Museum of Palace Collection as an example for the implementation of the suggested evaluation process. For example, the maximum illuminance in showcases was controlled best in the indirect general lighting alternatives (LA-3, LA-6, LA9, LA-12). So, lighting arrangements (LA) 3, 6, 9, and 12 are classified as Grade 1 according to the 'maximum illuminance' criterion (Table 2, line 4, column 3). To keep the maximum illuminance below the allowed limit for objects of low and medium sensitivity was taken as the most important criterion to be met. Also the properties of the historical exhibition room can be perceived best in the indirect general lighting alternatives. The most positive results in terms of illuminance uniformity and shadow properties in showcases were acquired in the Alternative A (LA-1, LA-2, LA-3), followed by the Alternative $C$ (LA-7, LA-8, LA-9). Thus, lighting arrangements 1, 2, 3 are rated with Grade 1 (Table 2, line 5, column 3) while lighting arrangements 7, 8, 9 are assigned with Grade 2 (Table 2, line 5, column 4) in relation to the criterion 'illuminance uniformity'. The maximum illuminance regarding freestanding displays on the platforms and behind the glass partitions was controlled successfully in all lighting alternatives. Nevertheless, the allowed illuminance of $200 \mathrm{~lx}$ could be reached easily in the indirectdirect general lighting alternatives (LA-2, LA-5, LA-8, LA-11) while the produced illuminance was lower in the other lighting alternatives. 
Table 2. Grading of lighting arrangements in terms of the criteria being considered

\begin{tabular}{|c|c|c|c|c|c|}
\hline \multirow{2}{*}{\multicolumn{2}{|c|}{ Lighting design criterion }} & \multicolumn{4}{|c|}{ Grading } \\
\hline & & \multirow{2}{*}{$\begin{array}{c}\text { Grade } 1 \\
2,5,8 \\
11\end{array}$} & \multirow{2}{*}{$\begin{array}{c}\text { Grade } 2 \\
1,4,7 \\
10\end{array}$} & \multirow{2}{*}{$\begin{array}{c}\text { Grade } 3 \\
3,6,9 \\
12\end{array}$} & \multirow{2}{*}{$\begin{array}{c}\text { Grade } 4 \\
-\end{array}$} \\
\hline \multirow{2}{*}{$\begin{array}{l}\text { General } \\
\text { lighting }\end{array}$} & $\begin{array}{l}\text { Average } \\
\text { illuminance }\end{array}$ & & & & \\
\hline & $\begin{array}{l}\text { Illuminance } \\
\text { uniformity }\end{array}$ & $\begin{array}{c}3,6,9 \\
12 \\
\end{array}$ & $\begin{array}{c}2,5,8 \\
11 \\
\end{array}$ & $\begin{array}{c}1,4,7 \\
10 \\
\end{array}$ & - \\
\hline \multirow{2}{*}{$\begin{array}{l}\text { Showcase } \\
\text { lighting }\end{array}$} & $\begin{array}{l}\text { Maximum } \\
\text { illuminance }\end{array}$ & $\begin{array}{c}3,6,9 \\
12\end{array}$ & $\begin{array}{c}1,4,7 \\
10 \\
\end{array}$ & $\begin{array}{c}2,5,8 \\
11\end{array}$ & - \\
\hline & $\begin{array}{l}\text { Illuminance } \\
\text { uniformity }\end{array}$ & $1,2,3$ & $7,8,9$ & $4,5,6$ & $\begin{array}{c}10,11, \\
12\end{array}$ \\
\hline \multirow{2}{*}{$\begin{array}{l}\text { Platform } \\
\text { lighting }\end{array}$} & $\begin{array}{l}\text { Maximum } \\
\text { illuminance }\end{array}$ & $\begin{array}{c}2,5,8 \\
11\end{array}$ & $\begin{array}{c}1,4,7 \\
10 \\
\end{array}$ & $\begin{array}{c}3,6,9 \\
12\end{array}$ & - \\
\hline & $\begin{array}{l}\text { Illuminance } \\
\text { uniformity }\end{array}$ & $\begin{array}{c}3,6,9 \\
12\end{array}$ & $\begin{array}{c}2,5,8 \\
11\end{array}$ & $\begin{array}{c}1,4,7 \\
10\end{array}$ & - \\
\hline \multirow{2}{*}{$\begin{array}{l}\text { Glass } \\
\text { partition } \\
\text { zone lighting }\end{array}$} & $\begin{array}{l}\text { Maximum } \\
\text { illuminance }\end{array}$ & $\begin{array}{c}2,5,8 \\
11 \\
\end{array}$ & $\begin{array}{c}1,4,7 \\
10 \\
\end{array}$ & $\begin{array}{c}3,6,9 \\
12 \\
\end{array}$ & - \\
\hline & $\begin{array}{l}\text { Illuminance } \\
\text { uniformity }\end{array}$ & $\begin{array}{c}3,6,9 \\
12\end{array}$ & $\begin{array}{c}1,5,8 \\
11 \\
\end{array}$ & $\begin{array}{c}2,4,7 \\
10 \\
\end{array}$ & - \\
\hline \multirow[b]{2}{*}{ Direct glare } & General lighting & $\begin{array}{c}3,6,9 \\
12 \\
\end{array}$ & $\begin{array}{c}2,5,8 \\
11 \\
\end{array}$ & $\begin{array}{c}1,4,7 \\
10 \\
\end{array}$ & - \\
\hline & $\begin{array}{l}\text { Showcase } \\
\text { lighting }\end{array}$ & $\begin{array}{c}7,8,9 \\
10 \\
11,12 \\
\end{array}$ & $4,5,6$ & $1,2,3$ & - \\
\hline \multirow{2}{*}{$\begin{array}{l}\text { Glare by } \\
\text { reflection }\end{array}$} & General lighting & $\begin{array}{c}3,6,9 \\
12\end{array}$ & $\begin{array}{c}1,2,4,5 \\
7,8,10 \\
11\end{array}$ & - & - \\
\hline & $\begin{array}{l}\text { Showcase } \\
\text { lighting }\end{array}$ & $\begin{array}{c}7,8,9 \\
10 \\
11,12 \\
\end{array}$ & $4,5,6$ & $1,2,3$ & - \\
\hline $\begin{array}{l}\text { Shadow } \\
\text { attributes }\end{array}$ & $\begin{array}{l}\text { Showcase } \\
\text { lighting }\end{array}$ & $1,2,3$ & $7,8,9$ & $4,5,6$ & $\begin{array}{c}10,11 \\
12\end{array}$ \\
\hline \multicolumn{2}{|c|}{ Perceptibility of the hall } & $\begin{array}{c}3,6,9 \\
12 \\
\end{array}$ & $\begin{array}{c}2,5,8 \\
11 \\
\end{array}$ & $\begin{array}{c}1,4,7 \\
10 \\
\end{array}$ & - \\
\hline
\end{tabular}

The following arrangements can be considered optimum regardless of energy consumption and only taking into account the criteria listed in Table 2:

- LA-2: Indirect-direct general lighting and showcase lighting with horizontal linear lamp behind the opal glass

- LA-3: Indirect general lighting and showcase lighting with horizontal linear lamp behind the opal glass

- LA-8: Indirect-direct general lighting and showcase lighting with horizontal linear luminaire behind the upper metal profile

- LA-9: Indirect general lighting and showcase lighting with horizontal linear luminaire behind the upper metal profile

However, the number of high or medium sensitive objects displayed in showcases is much more than the freestanding medium sensitive or insensitive objects. Precaution of lightinduced damage can be ensured well in showcases in the alternatives LA-3 and LA-9. On the contrary, the aimed illuminance of $200 \mathrm{~lx}$ for freestanding objects can be acquired in 
the alternatives LA-2 and LA-8, while the illuminance on these objects is lower in the alternatives LA-3 and LA-9. LA-3 and LA-9 should be preferred given the priority to the conservation of the objects rather than to the lower as aimed level of illuminance. Direct general lighting is the most economical choice if only the energy consumption is considered. The most economical showcase lighting option among alternatives treated in this study is Alternative B, followed by Alternative D, C, and A, respectively. However, appropriate lighting solutions should be determined in accordance with the features of the exhibited objects and the display technique, taking into account the main objectives of museum lighting. Afterwards, the most economical way can be chosen to implement the solutions in practice. In this context when also energy conservation along with the design criteria is taken into consideration, it can be concluded that the optimal lighting arrangement for the conditions of this study is LA-9, followed by LA-3.

The main objectives of artificial lighting in museums are to ensure the visitors perceive the properties of exhibited objects completely and comfortably, to protect these objects from being damaged, and energy efficiency. A further objective can be the perceptibility of the exhibition hall if it has historical characteristics and/or exceptional architecture. The purpose of this study is to suggest some missing guidelines in museum lighting, to compare different lighting alternatives in terms of conservation, visual comfort, and energy consumption, and to present an approach to evaluate different alternatives. The Museum of Palace Collections was dealt with in order to apply different approaches that will be the basis for comparison. To illuminate the exhibition hall, three alternatives for general lighting and four alternatives for showcase lighting were created and twelve different lighting arrangements were obtained with various combinations of these alternatives. In order to limit the conditions of the study, the existing showcase types, furnishings, and the exhibition design were kept constant. It is obvious that more lighting alternatives can be developed by taking into account other types of showcases, furnishings and exhibition design in addition to the existing ones. For the dome ceiling and the glass partition zone, a single lighting design was developed that was used for all lighting alternatives. Since the required illuminance for the platforms were attained by general lighting, no additional local lighting is planned. The aim was not to exceed the maximum permissible illuminance according to the sensitivity category of the objects in the showcases, on the platforms, and behind the glass partitions in all lighting alternatives. Thus, the effect of photochemical reaction was 
limited and the objects were protected with regard to illuminance.

The results achieved in the twelve arrangements were compared in terms of illuminance level and uniformity, direct glare, reflected glare, shadow properties, perceptibility of the hall, and energy efficiency. The number of lighting design criteria that met the requirements and their degree of fulfilment were considered in comparison. When the lighting arrangements suggested were evaluated in terms of the lighting criteria considered in this study, it was ascertained that the optimum lighting arrangements were indirect-direct general lighting and showcase lighting with horizontal linear lamp behind the opal glass (LA-2), indirect general lighting and showcase lighting with horizontal linear lamp behind the opal glass (LA-3), indirect-direct general lighting and showcase lighting with horizontal linear luminaire behind the upper metal profile (LA8), indirect general lighting and showcase lighting with horizontal linear luminaire behind the upper metal profile (LA9). The comparison in terms of energy consumption revealed the following order aligned from the most economical to the most expensive: LA-4, LA-10, LA-7, LA-6, LA-12, LA-1, LA-9, LA-3, LA5, LA-11, LA-8, LA-2. It is meaningful to apply indirect or indirect-direct lighting types in spaces having light coloured and matte ceiling. The application of indirect and direct-indirect lighting as general lighting alternatives in the exhibition hall with dark ceiling has caused energy consumption to be high in the related alternatives. The reason for considering these lighting types in this study was to bring out other options than direct lighting to avoid direct glare and/or reflected glare. Besides, the perception of this specific historical exhibition hall can be ensured best in the indirect general lighting alternatives. When the results obtained are evaluated together from the viewpoint of lighting criteria and energy consumption, the optimum lighting arrangements for the conditions of this study were determined as 'indirect general lighting and showcase lighting with horizontal linear luminaire behind the upper metal profile (LA-9)', followed by 'indirect general lighting and showcase lighting with horizontal linear lamp behind the opal glass (LA-3)'. The evaluation process suggested in this study and discussed via the Museum of Palace Collections as an example can be followed in making the most rational decision regarding the illumination of other halls.

Architectural-, interior-, lighting-, and display design should be performed simultaneously in order to protect the artefacts exhibited in a museum, to ensure the perception of these in a comfortable and complete manner, and to assure the energy efficiency. Otherwise, it is inevitable to compromise at least one 
of the subjects mentioned, namely the conservation of objects, the provision of visual comfort and the energy savings.

\section{ACKNOWLEDGEMENT}

The authors would like to thank to the Museum and Publicity Presidency of General Secretariat of Turkish Grand National Assembly (National Palaces) for the permission and to the responsible persons of the museum, Ms. Güller Karahüseyin and Mr. Vehbi Cem Çelik for the support during the investigation of the Museum of Palace Collections.

\section{REFERENCES}

CEN: European Committee for Standardization (2014). Conservation of Cultural Heritage- Guidelines and Procedures for Choosing Appropriate Lighting for Indoor Exhibitions. EN 16163, Brussels.

CEN: European Committee for Standardization (2011). Light and Lighting-Lighting of Work Places - Part 1: Indoor Work. EN 12464-1, Brussels.

CIE: International Commission on Illumination (2004). Control of Damage to Museum Objects by Optical Radiation. CIE 157, Vienna.

Csuti, P., Fay, A., Schanda, J. et.al. (2015). "Colour fidelity for picture gallery illumination, Part 2: Test sample selectionmuseum tests", Lighting Research and Application, 47: 522532.

Çelikmez, T. (2017). Sergileme Hacmi Aydınlatma Alternatiflerinin Karşılaştırılması: Saray Koleksiyonları Müzesi Örneği (Comparison of Exhibition Room Lighting Alternatives: The Palace Collections Museum as an Example). MSc Thesis, Ylldız Technical University, Istanbul.

Druzik, J.R., Michalski, S.W. (2011). Guidelines for Selecting SolidState Lighting for Museums. Report for Canadian Conservation Institute, http://www.connectingtocollecti ons.org/wp-content/uploads/2011/08/SSL-Guidelines-Ve r.-10.0.pdf. Access date 19 August 2018.

Feltrin, F., Leccese, F., Hanselaer, P. et.al. (2017). "Analysis of Painted Artworks' Color Appearance Under Various Lighting Settings", IEEE International Conference on Environment and Electrical Engineering, 6-9 June 2017, https://ieeexplore.ieee.org/document/7977574, Italy.

FGL: Fördergemeinschaft Gutes Licht, Good Lighting for Museums, Galleries and Exhibitions (2018) Booklet 18, https://www.licht.de/fileadmin/Publications/lichtwissen/ 0703_lw18_E_light_museums_galleries_web.pdf. Access date 19 August 2018. 
Garside, D., Curran, K., Korenberg, C. et. al. (2017). "How is museum lighting selected? An insight into current practice in UK museums", Journal of the Institute of Conservation, 40: 3-14.

ICOM: International Council of Museums (2004). Running a Museum: A Practical Handbook. Paris.

IESNA: Illuminating Engineering Society of North America (2000). Lighting Handbook. $9^{\text {th }}$ ed. New York.

IESNA: Illuminating Engineering Society of North America (1996). Museum and Art Gallery Lighting: A Recommended Practice. RP-30-96, New York.

Kılıç, H. (1985). Çağdaş Aydınlatma Tekniği ve Günümüz Müzeciliği Verilerine Göre Müze Yapıları İçin Yeni Bir Mimari Yaklaşım (A New Architectural Approach for Museum Buildings According to Contemporary Lighting Technique and Current Museology Data). PhD Thesis, Ylldız Technical University, Istanbul.

Luo, H.W., Chen, H.S., Chou, C.J. et. al. (2016). "Improving museum lighting: new experiments in perception and the colour changes caused by white LED lighting", Stud. Conserv, 61: 302-304.

Scuello, M., Abramov, I., Gordon, J., et. al. (2004). "Museum Lighting: Optimizing the Illuminant", Color Res Appl, 29: 121-127.

Vidovszky- Németh, A., Kosztyán, Z.T. (2016). "Introductory experiments on preferred picture illuminations", IEEE Lighting Conference of the Visegrad Countries, 13-16 September 2016, https://ieeexplore.ieee.org/document/ 7745516, Poland.

Wilson, M. (2006). "Lighting in museums: Lighting interventions during the European demonstration project 'Energy efficiency and sustainability in retrofitted and new museum buildings' (NNES-1999-20)", Int. J. Sustainable Energy, 25 (3-4): 153-169. 


\section{Resume}

Taner Çelikmez, M.Arch., graduated from Ylldız Technical University in 2012 as an architect and received his MSc degree in Building Physics from Ylldız Technical University in 2017. He works as an architectural projects manager in Construction Investments Directorate at LC Waikiki.

Leyla Dokuzer Öztürk, Prof.Dr., studied Architecture at Yıldız Technical University and obtained her MSc degree in Building Physics and PhD in Lighting in the same university. Despite being involved in all building physics topics, her areas of specialization are lighting, energy efficiency, luminaire design, and colour. She is one of the founders of the Turkish National Committee on Illumination and is the country member of Division 3 of CIE. At present, she is an academic lecturer at Faculty of Architecture in Ylldız Technical University. 